\title{
Challenges in Measuring Effectiveness Using the Prevention of Mother to Child Transmission of HIV/AIDS (PMTCT) Indicators in the South West Region, Cameroon
} \author{
Esther Teng Mbong ${ }^{3}$, Terrence Beteck Epie ${ }^{2,4}$, Fala Bede ${ }^{2}$ and Samuel Nambile Cumber ${ }^{5,6,7}$ \\ ${ }^{1}$ Department of Microbiology and Parasitology, University of Buea, Cameroon \\ ${ }^{2}$ HIV Free Project, Cameroon Baptist Convention Health Services, Cameroon \\ ${ }^{3}$ Pan African University of Life and Earth Science Institute, University of Ibadan-Nigeria, Nigeria \\ ${ }^{4}$ Department of Medicine, University of Oxford, United Kingdom \\ ${ }^{5}$ Department of Public Health and Community Medicine, University of Gothenburg, Sweden \\ ${ }^{6}$ School of Health Systems and Public Health, University of Pretoria Private Bag X323, South Africa \\ ${ }^{7}$ Faculty of Health Sciences, University of the Free State, South Africa
}

Zennobia Vecheusi Viyoff',2, Claude Ngwayu Nkfusai ${ }^{1,2 *}$, Frankline Nsai Sanyuy ${ }^{2}$, Ngwene Hycentha Diengou $^{1}$,

Submission: August 14, 2019; Published: September 10, 2019

*Corresponding author: Claude Ngwayu Nkfusai, Cameroon Baptist Convention Health Services (CBCHS), Cameroon

\begin{abstract}
Background: Data on PMTCT indicators such as HIV prevalence in pregnant women, percentage of HIV+ pregnant women and HIV exposed infants (HEI) receiving treatment and mother to child transmission rate (MTCT) was obtained from the Regional Delegation of Public Health in the South West Region for the period 2011-2013. We therefore, decided to determine the Challenges in Measuring Effectiveness using the Prevention of Mother to Child Transmission of HIV/AIDS (PMTCT) Indicators in the South West Region of Cameroon.
\end{abstract}

Methods: A cross-sectional study was carried out through the administration of a structured questionnaire to health workers in 4 health districts to identify challenges faced in effective implementation of the PMTCT program.

Result: Staffing, service accessibility and community level factors particularly stigma, fear of disclosure and lack of partner's support have not changed 10 years after the introduction of the program. The most prevalent challenges faced by health workers were staff shortages (73.4\%) and lack of male involvement in the PMTCT program (60.9\%), and in pregnant women poverty (68.8\%) and stigmatisation (54.7\%).

Conclusion: Therefore, constant monitoring of PMTCT indicators, integration of PMTCT services, training, recruitment of staff and assisting pregnant women have a better understanding could improve utilisation and implementation of PMTCT services.

Keywords: Challenges; Indicators; PMTCT; South west; Cameroon

\section{Introduction}

First, some data on PMTCT indicators are commonly collected from several patient registers in the form of unlinked monthly summary reports [1]. Consequently, data on the number of pregnant women who tested HIV positive, received prophylaxis and HEI who received prophylaxis are not readily available. To obtain linked data, patient registers would need to be thoroughly cross-checked which would be time consuming and cumbersome. Secondly, the reported HIV prevalence in pregnant women is typically derived from those accepting voluntary counselling and testing. These women have a lower prevalence than those who refuse testing, probably because women at risk of HIV are less likely to volunteer for testing [2]. Thirdly, in countries where same 
day HIV testing is unavailable, 15-67\% of women who are tested do not obtain their test results hence may not receive prophylaxis [3].

Fourthly, none of the indicators objectively measure adherence to the prophylactic drugs and there can be substantial discordance between the proportion of women who agree to prophylaxis and the proportion of women who actually take the drugs. Fifthly, most indicators of program's effectiveness are quantitative rather than qualitative. The quality of services offered at health facilities affects supply and demand for voluntary testing, uptake of antiretroviral drugs, and other activities such as family planning [4]. Also, current indicators do not capture possible adverse effects of the activities whether related to the antiretroviral drugs or to the revelation of maternal or child infection status (such as stigmatisation and domestic violence). Current indicators fail to evaluate effectiveness in terms of coverage and linkage to care for mothers, infants, and family members [5].

The MDGs were set with objectives to enable $90 \%$ of HIV+ pregnant women and HEI receive ARVs to prevent HIV transmission and to reduce mother to child transmission by <5\%. In 2011, only $54 \%$ of HIV positive pregnant women in Cameroon received ARVs to prevent HIV transmission to their infants. The estimated rate of mother to child transmission (MTCT) was $24 \%$ (DHS-MICS, 2011). It is evident therefore that there are some hurdles to effective implementation of PMTCT services.

Data collected and reported in public health systems across all levels cannot be assumed to be complete and accurate enough to track process performance or outcomes for PMTCT care. As proposed by Mate KS, et al. [6], regular evaluations should be done to ensure effective usage of the program and also addressing those health care providers who will be most instrumental in making the program work better under existing conditions. Thus, it is essential to understand the utilisation of the PMTCT program based on the perspective of health care providers to continue to address the current situation (prevalence of HIV in pregnant women was 7.6\% in Cameroon) (Cameroon's Operational Plan Report, 2013). Therefore, an evaluation of the PMTCT services in the South West Region can reveal the advancements made and the hurdles faced by health workers during implementation. We, therefore, decided to determine the Challenges in Measuring Effectiveness using the Prevention of Mother to Child Transmission of HIV/AIDS (PMTCT) Indicators in the South West Region of Cameroon.

\section{Methods}

\section{Study Design}

A retrospective study was carried out on PMTCT indicators (prevalence of HIV/AIDS in pregnant women, percentage of HIV pregnant women and HEI receiving treatment and the mother to child transmission rate) for the period 2011-2013 based on the availability of the data.

A multi-stage cross-sectional study was carried out through the administration of a structured questionnaire to health workers to investigate challenges affecting the effectiveness of the program. Four health districts were selected from 18. Two health districts (HDs) having low prevalence between $0 \%$ and 5\% in 2013 were selected (Fontem 2.0\% and Konye 5.0\%) and the other two for high prevalence between $6 \%$ and $10 \%$ (Tiko $6.9 \%$ and Ekondotiti $8.0 \%$ ). The district hospital and four health areas were selected from each health district making a total of five health facilities in each health district.

\section{Sample Size Calculation}

$$
n=\left[\frac{\frac{p(1-p)}{\frac{A 2}{Z 2}+\frac{p(1-p)}{N}}}{R}\right]
$$

Where:

$\mathrm{n}=$ Sample size required

$\mathrm{N}=$ Number of health workers implementing PMTCT Program in the population: (100)

$\mathrm{P}=$ Estimated variance in population, as a decimal: 0.5 for 50-50)

$\mathrm{A}=$ Precision desired, expressed as a decimal: $(0.05$ for $5 \%)$

$\mathrm{Z}=$ Confidence level: 1.96 for $95 \%$ confidence

$\mathrm{R}=$ Estimated Response rate, as a decimal: (1)

Applying the formula:

$$
n=\frac{0.5(1-0.5)}{\frac{0.05^{2}}{1.96^{2}}+\frac{0.5(1-0.05)}{100}} / 1
$$

$\mathrm{n}=79.34$ respondents and it was increased to 80 respondents.

Twenty respondents from each health district (80 respondents divided by 4 health districts). Four health workers were to be evaluated from each health facility.

\section{Inclusion Criteria}

a) Health worker's resident in the health districts who accepted to participate and gave their consent.

b) Health workers involved in the PMTCT program.

c) Working experience of 1 year and above.

d) All sexes, $21 \mathrm{yrs}$ to $60 \mathrm{yrs}$.

\section{Exclusion Criteria}

a) Health workers not resident in the health district.

b) Health workers not involved in the PMTCT Program.

c) Working experience less than 1 year.

d) Age less than 21 years. 


\section{Study Area}

The South West Region is made up of 18 health districts and this study covered four health districts (Ekondotiti, Fontem, Konye and Tiko) based on the prevalence of HIV/AIDS in pregnant women in 2013. Health facilities selected are shown in Figure 2.

\section{Study Population}

The study population was made up of health workers from four health districts implementing the PMTCT program.

\section{Data collection, Analysis and Interpretation}

Data on PMTCT indicators was obtained from the Regional Delegation of Public Health in Buea based on availability of data for the period 2011-2013. Data was assessed for completeness, consistency, reliability, appropriate presentation and accessibility. Data was organised in Microsoft Soft (MS) Excel 2007 and analysed. Progress in access and utilisation of PMTCT services across the PMTCT cascade was described using percentages and numeric representations.
Data collected from health workers by questionnaire (Appendix IV) was tabulated and analysed using the Statistical Package for Social Sciences (SPSS) version 17 and MS Excel 2007. Results were illustrated using Figures. Chi square test was used to test for an association between socio-demographic variables (age, sex, length of involvement in PMTCT and health worker category) and health worker's knowledge of PMTCT guidelines and training and $\mathrm{a}<<0.05$ was considered statistically significant.

\section{Ethical Considerations}

Ethical clearance was obtained from the Faculty of Health Science Institutional Review Board (IRB) and administrative authorisation was obtained from Regional Delegation for Public Health in the South West Region.

\section{Results}

\section{Availability of PMTCT services}

Of those who responded to the questionnaire, ANC, FP and ARV prophylaxis were available in the respective facilities. CD4 count and treatment centre were the least available services (Figure 1).

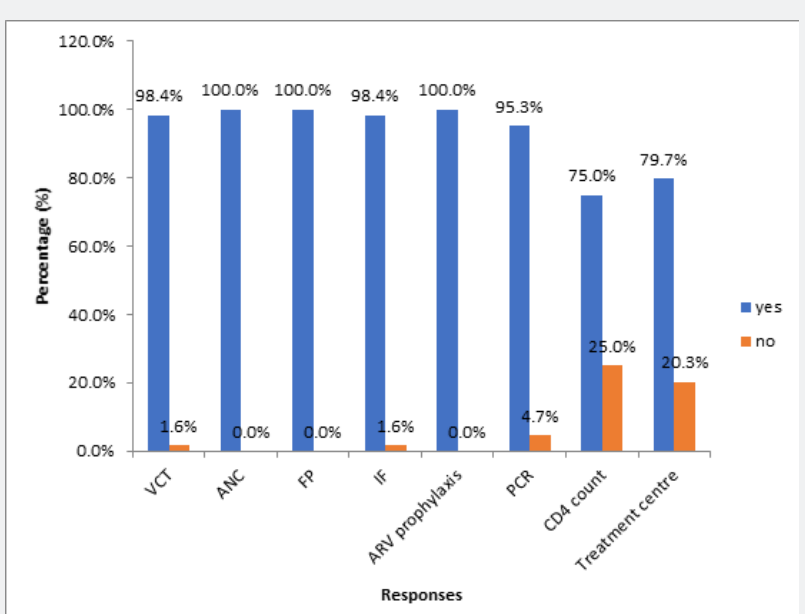

Figure 1: Availability of PMTCT services in health facilities.

\section{Challenges faced by Health Care Workers}

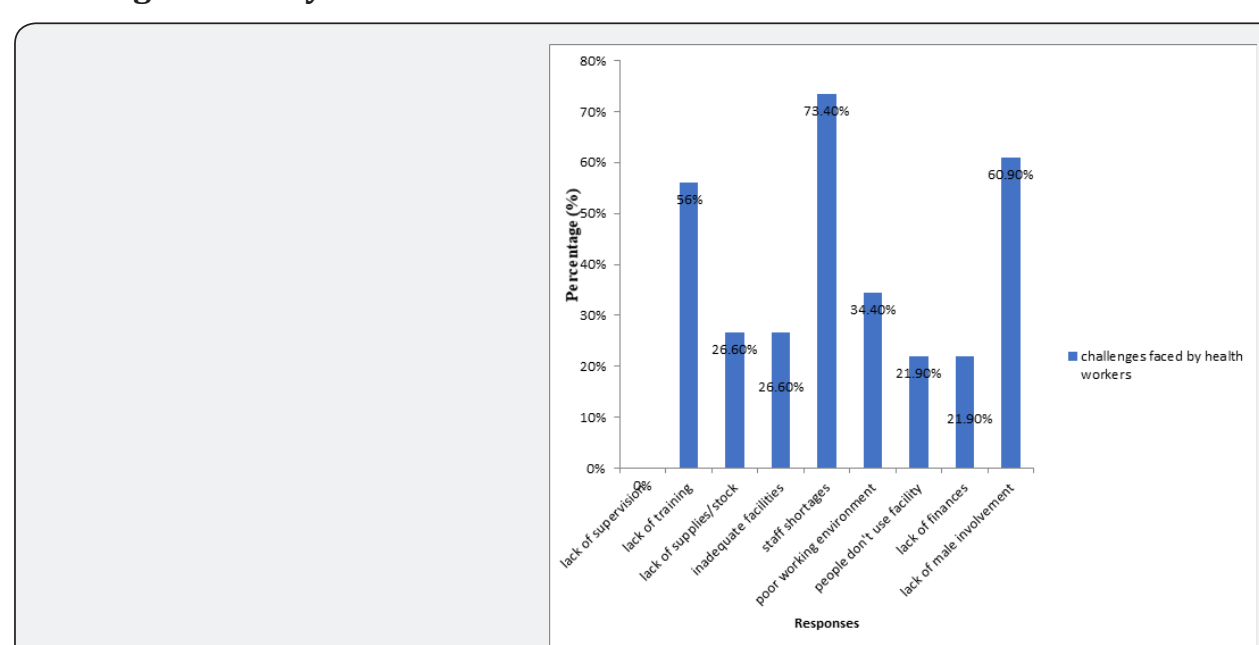

Figure 2: Challenges faced by health workers in implementing the program. 
Health workers could choose more than one challenge. The prevalent challenges reported were staff shortages and lack of male partner's involvement and lack of training (Figure 2). The rest of the challenges had a prevalence rate range of $21.9-34.4 \%$.

\section{Challenges HIV+ Pregnant Women Face in completing PMTCT}

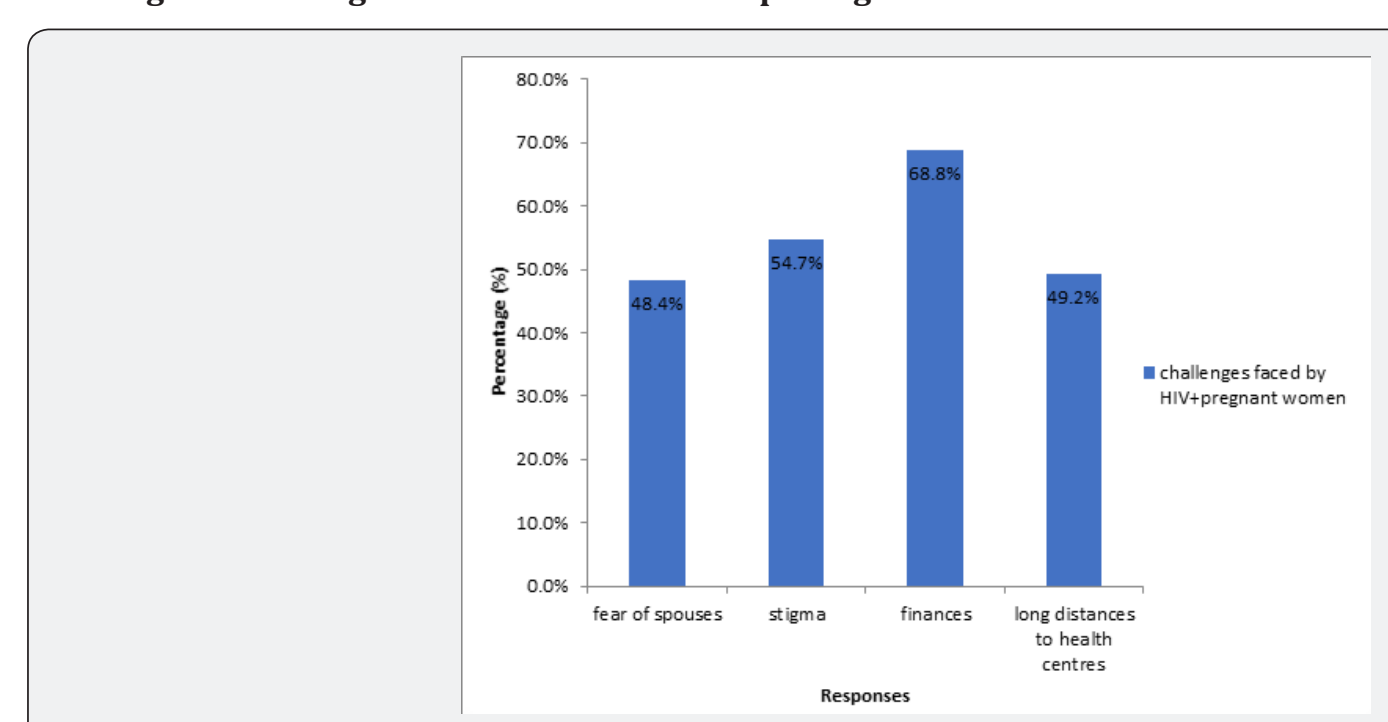

Figure 3: Challenges in completing PMTCT by HIV pregnant women.

The prevalent challenge resulting in HIV pregnant women not following up the complete PMTCT program was lack of finances (Figure 3).

\section{Discussion}

The prevalent challenges reported were lack of male involvement and staff shortages and lack of training. Male involvement is a key factor in preventing mother to child transmission because if partners are involved during ANC visits, the fear of non-disclosure would not exist and large number of drop-outs will not be recorded. Lack of male involvement causes problems in family planning. Staff shortages are common in health centres in Cameroon, with one health worker being involved in the implementation of all services. This could be tiring and ineffective. The problem of salaries and bonuses comes into play here if more health workers have to be recruited, trained and sent to rural areas where services are greatly needed.

Nuwagabe et al. [7] reported shortage of PMTCT staff (counsellors, midwives and laboratory personnel) in all five hospitals under study. Shortages of supplies (laboratory reagents, disinfectants, sterile equipment and dressings) were reported to have occurred at all five sites. These challenges were also found in studies carried by Annabelle G, et al. [8]. The prevalent challenge faced by HIV+ pregnant mothers in completing the program and providing proper infant feeding was finances. This is common due to the rural nature of most health districts. Some cannot afford some services involved in the program leading to increased risk of transmission of HIV to babies. Most villages are far from health centres and so if the pregnant woman does not have money, she will not participate fully in the program (since treatment is taken at different periods in the PMTCT cascade).
Stigmatisation and fear of spouses are also common because she is scared to tell her spouse and family members.

\section{Conclusion}

a) The prevalence of HIV in pregnant women was $6.28 \%$, $6.31 \%$ and $5.87 \%$ in 2011, 2012 and 2013 respectively in the South West Region.

b) Health centres did not have all PMTCT services and health workers were not aware of some of the services in their health facilities.

c) Health workers involved in the PMTCT program did not know of PMTCT guidelines and had equally not been trained on all services in the program.

d) Long standing health system issues such as staffing and service accessibility and community level factors particularly stigma, fear of disclosure and lack of partner's support were identified as challenges in full implementation of the PMTCT program.

\section{Limitations of this Study}

This study was conducted largely in public health facilities thus transferability of the findings to other public health facilities in South West Region is possible. However, the findings may not apply in the non-profit or private health facilities where constraints and priorities may be different. The sample size could not be reached.

\section{Authors' Contributions}

ZVV, CNN, FNS, NHD, ETM, TBE, FB and SNC conceived and designed the study. ZVV implemented the study and conducted 
data analysis. ZVV, CNN, FNS, NHD, ETM, TBE, FB and SNC interpreted study results: ZVV and NCN wrote the first draft of the manuscript. ZVV, CNN, FNS, NHD, ETM, TBE, FB and SNC reviewed and corrected the draft manuscript. All authors read and approved the final manuscript.

\section{Previous Studies Have Been on}

a) Barriers and facilitating factors to the uptake of antiretroviral drugs for prevention of mother-to-child transmission of HIV in sub-Saharan Africa: a systematic review

b) Routine intrapartum HIV counselling and testing for prevention of mother-to-child transmission of HIV in a rural Ugandan hospital

c) Challenges for Routine Health System Data Management in a Large Public Programme to Prevent Mother-to-Child HIV Transmission

\section{What the Study Adds}

i. Health workers involved in the PMTCT program did not know of PMTCT guidelines and had equally not been trained on all services in the program.

ii. Long standing health system issues such as staffing and service accessibility and community level factors particularly stigma, fear of disclosure and lack of partner's support were identified as challenges in full implementation of the PMTCT program.

\section{Acknowledgement}

We are grateful to all the women who participated in this research.

\section{References}

1. Sherman GG, Jones SA, Coovadia AH, Urban MF, Bolton KD, et al. (2004) PMTCT from research to reality-results from a routine service. S Afr Med J 94(4): 289-292.

2. Stringer EM, Ekouevi DK, Coetzee D, Tih PM, Creek TL, et al. (2005) Coverage of nevirapine-based services to prevent mother to-child HIV transmission in 4 African countries. Journal of Acquired Immune Deficiency Syndromes 32(5): 506-513.

3. Doherty T, Chopra M, Nkonki L, Jackson D, Greiner T, et al. (2005) Effect of the HIV epidemic on infant feeding in South Africa: When they see me coming with the tins they laugh at me. Bull World Health Organ 84(2): 90-96.

4. Perez E, Peña R, Tavarez-Rojas M, Peña C, Quinonez S, et al. (2003) Preventing mother-to-child transmission in a developing country: The Dominican Republic experience. J Acquir Immune Defic Syndr 34(5): 506-511.

5. Ayouba A, Tene G, Cunin P, Foupouapouognigni Y, Menu E, et al. (2003) Low rate of mother-to-child transmission of HIV1 after nevirapine intervention in a pilotpublic health program in Yaoundé, Cameroon. J Acquir Immune Defic Syndr 34(3): 274-280.

6. Mate KS, Bennett B, Mphatswe W, Barker P, Rollins N, et al. (2009) Challenges for Routine Health System Data Management in a Large Public Programme to Prevent Mother-to-Child HIV Transmission in South Africa. Plos One 4(5): e5483-e5500.

7. Nuwagaba-Biribonwoha H, Mayon-White RT, Okong P, Carpenter LM (2007) Challenges faced by health workers in implementing the prevention of mother-to-child HIV transmission (PMTCT) programme in Uganda. J Public Health (Oxf) 29(3): 269-274.

8. Annabelle G, Isolde B, Gitau M, Kate I, Alison W, et al. (2013) Barriers and facilitating factors to the uptake of antiretroviral drugs for prevention of mother-to-child transmission of HIV in sub-Saharan Africa: a systematic review. J Int AIDS Soc 16(1): 18588.

\begin{tabular}{l} 
Your next submission with Juniper Publishers \\
will reach you the below assets \\
- Quality Editorial service \\
- Swift Peer Review \\
- Reprints availability \\
- E-prints Service \\
- Manuscript Podcast for convenient understanding \\
- Global attainment for your research \\
- Manuscript accessibility in different formats \\
( Pdf, E-pub, Full Tsext, Audio) \\
- Unceasing customer service \\
Track the below URL for one-step submission \\
https://juniperpublishers.com/online-submission.php \\
\hline
\end{tabular}

